\title{
Correction to: The effectiveness of Pictorial Representation of Illness and Self Measure (PRISM) for the assessment of the suffering and quality of interpersonal relationships of patients with chronic pain
}

\author{
Mitsunao Tomioka ${ }^{1 *}$, Masako Hosoi ${ }^{1,2,3}$, Tomona Okuzawa $^{4}$, Kozo Anno $^{2}$, Rie Iwaki ${ }^{2}$, Hiroshi Kawata ${ }^{5}$,
} Chiharu Kubo ${ }^{6}$ and Nobuyuki Sudo 1,2,3

Correction to: BioPsychoSocial Med 15, 22 (2021). https://doi.org/10.1186/s13030-021-00223-0

Following publication of the original article [1], the authors identified an error in Fig. 3 and Table 6.

In the old Fig. 3, there was a layout problem in the upper right part of the figure. The word "tests" in the sentence " 7 were fit. But it had completed outpatient PRISM and pain-related tests" was out of the box.

In the old Table 6, eight respondents were shown for the two questions, each person's comment consisted of two comment parts before (T0) and after (T1). The old table cannot distinguish between them. The author put the replaced shapes in the table in the extended metafile so that it wouldn't get out of shape.

The correct figure and table have been included in this correction, and the original article has been corrected.

\section{Author details}

'Department of Psychosomatic Medicine, Graduate School of Medical Sciences, Kyushu University, 3-1-1 Maidashi, Higashi-ku, Fukuoka 812-8582, Japan. ${ }^{2}$ Department of Psychosomatic Medicine, Kyushu University Hospital, 3-1-1 Maidashi, Higashi-ku, Fukuoka 812-8582, Japan. ${ }^{3}$ Multidisciplinary Pain Center, Kyushu University Hospital, 3-1-1 Maidashi, Higashi-ku, Fukuoka 8128582, Japan. ${ }^{4}$ Center for Dementia Related-Diseases, Konan Medical Center, 1-5-16 Kamokogahara, Higashinada-ku, Kobe, Hyogo 658-0064, Japan. ${ }^{5}$ Department of Psychosomatic Medicine, Kyushu Central Hospital of the Mutual Aid Association of Public School Teachers, 3-23-1 Shiobaru, Minami-ku, Fukuoka 815-8588, Japan. ${ }^{6}$ Nakamura Gakuen University, 5-7-1 Befu, Jounan-ku, Fukuoka 814-0198, Japan.

Published online: 25 January 2022

\section{Reference}

1. Tomioka M, et al. BioPsychoSocial. Medicine. 2021;15:22.
The original article can be found online at https://doi.org/10.1186/s13030021-00223-0

* Correspondence: tomioka.mitsunao.553@m.kyushu-u.ac.jp

'Department of Psychosomatic Medicine, Graduate School of Medical

Sciences, Kyushu University, 3-1-1 Maidashi, Higashi-ku, Fukuoka 812-8582, Japan

Full list of author information is available at the end of the article
() The Author(s). 2022 Open Access This article is licensed under a Creative Commons Attribution 4.0 International License, which permits use, sharing, adaptation, distribution and reproduction in any medium or format, as long as you give appropriate credit to the original author(s) and the source, provide a link to the Creative Commons licence, and indicate if changes were made. The images or other third party material in this article are included in the article's Creative Commons licence, unless indicated otherwise in a credit line to the material. If material is not included in the article's Creative Commons licence and your intended use is not permitted by statutory regulation or exceeds the permitted use, you will need to obtain permission directly from the copyright holder. To view a copy of this licence, visit http://creativecommons.org/licenses/by/4.0/ The Creative Commons Public Domain Dedication waiver (http://creativecommons.org/publicdomain/zero/1.0/) applies to the data made available in this article, unless otherwise stated in a credit line to the data. 
28 Outpatients All were eligible and Completed PRISM and pain related questionnaires at the time of outpatient consultation

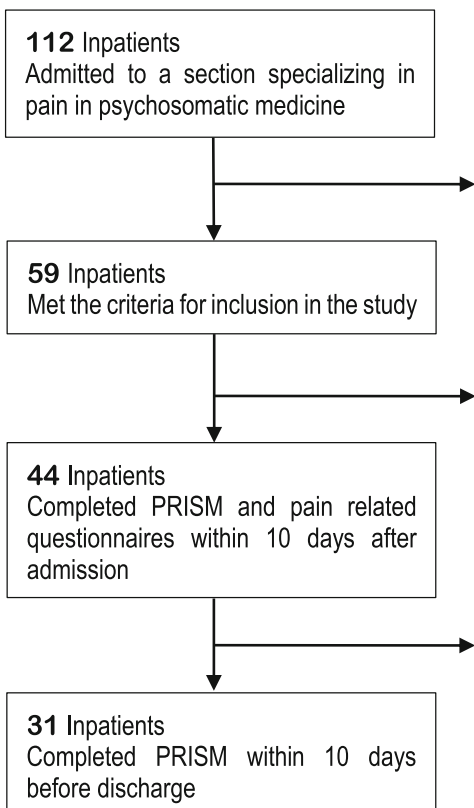

112 Inpatients

Admitted to a section speci

59 Inpatients

Met the criteria for inclusion in the study

15 Excluded

Did not complete pain related

questionnaires

13 Excluded

Did not complete PRISM within 10 days

before discharge

Fig. 3 Participant flowchart

Table 6 Changes in distance and patient comments on their medical care and significant others discs

Question: Please tell me your impression of your current medical care.

$\Delta \mathrm{SMcS}(\mathrm{cm})$ Comments

$\Delta \mathrm{SMcS}(\mathrm{cm}) \quad$ Comments

-20.2 T0 "The treatment is a little different than before, so I'm looking forward to it."

T1 "Now the doctors' treatment is 100\% suitable for my illness."

-13.8 T0 "I am not sure yet."

T1 "... My doctor eases my heart to some extent."
+21.4 T0 "My doctor gives me symptomatic treatment to prevent my pain."

T1 "...I have a feeling of distrust in the doctor because I have to be discharged."

+12.9 T0 "I feel that the method of treatment for my illness has been well established in the world"

T1 "My doctor complains that I'm thinking about too many various things."

Question: Why do you feel this person is important to you?

$\Delta \mathrm{SSoS}(\mathrm{cm}) \quad$ Comments

-12.4 T0 “... Family members say what they think directly, and their comments feel like a knife to my heart."

T1 "... I am grateful that my family members have supported me so far."

-12.0 T0 "My mother watches over her children equally from a distance."

T1 "My mother is worried about me." $\triangle \mathrm{SSoS}(\mathrm{cm}) \quad$ Comments

+14.2 T0 "My husband is kind and will do anything without making an unpleasant face."

T1 "My husband watches over me from a distance."

+3.7 T0 "Without my wife, daily life is difficult."

$\mathrm{T} 1$ “... My wife doesn't complain and silently accepts me.” 